\title{
O POTENCIAL ESTRATÉGICO DO DESIGN DE AMBIENTES NO PROCESSO DE RESSIGNIFICAÇÃO DE EDIFICAÇÃO SUBUTILIZADA: UMA PROPOSTA PARA A IGREJA SANTA ERMELINDA EM BELO HORIZONTE
}

Thaís Jahel Marigo

Escola de Design - Universidade do Estado de Minas Gerais

thaismarigo@gmail.com

Paula Glória Barbosa

Escola de Design - Universidade do Estado de Minas Gerais

paulaglbarbosa@gmail.com

Samantha Cidaley de Oliveira Moreira

Escola de Design - Universidade do Estado de Minas Gerais

samanthacidaley@gmail.com

Resumo: Espelhando-se nos exemplos de intervenção em edificações religiosas que não são mais utilizadas como tal, ação especialmente difundida na Europa e no Canadá, este trabalho apresenta o potencial estratégico do design de ambientes no processo de ressignificação de uma edificação subutilizada. O pensamento em design para o projeto de ambientes orientou $o$ processo de ressignificação de uma igreja subutilizada localizada em Belo Horizonte. Desenvolvido em 2015 como trabalho final de graduação em Design de Ambientes da Escola de Design da Universidade do Estado de Minas Gerais, o referido trabalho foi sistematizado em duas fases, ambas sob orientação docente. Na primeira, a estudante se dedicou às seguintes atividades: investigação de edificações religiosas com potencial de ressignificação; definição da edificação conforme proposta, enquadrando-a como objeto de estudo; levantamento de informações referentes ao contexto sociocultural no qual a edificação está inserida; e análise de possibilidades de uso para a edificação selecionada. Os dados coletados e análises realizadas indicaram a implantação de um café-sebo para ocupação dos ambientes do imóvel subutilizado. Na segunda fase, dispondo como estratégia o fluxo metodológico do design para ambientes, a graduanda se ateve ao projeto dos espaços internos e externos do café-sebo. Os resultados apresentados neste artigo confirmam o potencial estratégico do pensamento em design para ambientes no processo de ressignificação de edificações subutilizadas, uma vez que a proposta projetual leva à comunidade nova possibilidade de uso e novo significado sem perder a importância imagética da arquitetura e o valor cultural do imóvel para a região e, dentre outros benefícios, reduz espaços urbanos degradados e valoriza a memória associada ao lugar.

Palavras-chave: ressignificação; edificação religiosa; design de ambientes. 


\begin{abstract}
Inspired by intervention examples of religious building not used for what they were originally conceived, as seen on Canada and European countries, this article discusses under the lenses of interior design, the resignification proposal of an underused church in the city of Belo Horizonte in Brazil. In general, the idea of a resignification of an underused church and giving it a new use to the community around makes possible to reduce degraded urban spaces and to value the memory associated to the building. With the purpose of identifying the resignification of an underused church in Belo Horizonte and surrounding cities in mind, the following phases were defined: investigate religious buildings in Belo Horizonte and surrounding cities that had potential for a resignification on an environmental design project; select one of them as main study object; study new uses possibilities for the chosen building that was coherent with the current sociocultural context it was immersed; develop a design solution for the aforementioned building, with the purpose to promote the resignification of its spaces. Finally, at the end of the project, it was proposed a transformation into a library and coffee area, where the memory and imagination were present in the form of books, coffee and different form of artistic expression in a democratic space, that integrate and facilitates ideas and knowledge exchange between all publics and minds.
\end{abstract}

Keywords: resignification; religious building; interior design.

\title{
1. INTRODUÇÃO
}

O mundo contemporâneo tem sido marcado por mudanças profundas no comportamento das pessoas que se fazem refletir especialmente na apropriação e no abandono dos espaços da vida cotidiana. É relativamente comum, nas metrópoles e nas pequenas cidades interioranas de países diversos, encontrar edifícios residenciais, comerciais, institucionais ou industriais vazios e abandonados em diferentes proporções. Essa realidade também é percebida em relação às construções religiosas, como igrejas e capelas, por vezes degradadas pelo tempo e, não raro, em ruínas.

Na Europa, por exemplo, a ocorrência de edificações religiosas abandonadas, desativadas, subutilizadas ou degradadas é muito recorrente. Na Inglaterra, 20 igrejas, em média, são fechadas por ano. Na Dinamarca, aproximadamente 200 igrejas foram consideradas inviáveis ou subutilizadas até o final da década de 1990. A Igreja Romana Católica na Alemanha, por sua vez, fechou mais de 515 igrejas em fins do século XX. A situação parece mais crítica na Holanda, onde os líderes da Igreja Católica calculam que dois terços das suas 1.600 igrejas estarão desativadas em uma década, e estimam, ainda, que 700 igrejas protestantes holandesas estarão fechadas em menos de 4 anos. (BENDAVI, 2015).

No Canadá, presencia-se, também, esta realidade. Ermias Amayu (2014) afirma que mudanças nos valores sociais contemporâneos das comunidades urbanas canadenses resultaram em impactos significantes nas instituições religiosas e em seus edifícios. Com o contínuo declínio do número de frequentadores dos templos religiosos, muitos dos edifícios históricos estão sendo esvaziados por suas congregações. Para Kerstin Gothe e Stefan Netsch (2013), a principal causa da 
desativação de edifícios religiosos está relacionada aos altos custos de sua preservação, restauração e manutenção. Ademais, o fato de estarem abertas a um público vasto e variado, requer que essas edificações sejam adequadas constantemente às normas de acessibilidade e a outras questões de cunho prático e funcional.

Entretanto, muitas dessas igrejas são elementos centrais de suas comunidades, e muitos indivíduos são profundamente ligados a essas edificações, muitas vezes seculares. Nesse sentido, é muito comum que a comunidade dessas regiões se esforce para reinventar suas antigas igrejas. Na Holanda, por exemplo, há diversos casos que ilustram a possibilidade de edificações religiosas se adaptarem a um novo contexto de uso. Em Arnhem, uma igreja de 1889 foi ocupada por uma loja de roupas e, em Maastricht, uma igreja dominicana do século XIII foi transformada em uma livraria (BENDAVI, 2015).

Neste ponto, cabe ressaltar que quanto maior for a iconicidade da igreja, mais difícil é encontrar um uso adequado para ela. Ainda de acordo com Gothe e Netsch (2013), é mais fácil a comunidade aceitar um novo uso para uma igreja do pós-guerra em um quarteirão urbano do que para a igreja principal de uma cidade. Usualmente, a tipologia do novo contexto de uso e a acessibilidade que esse edifício terá ao público são fatores determinantes para a definição e a aceitação dessa transformação pela comunidade.

Jane Jacobs (1961) afirma ser quase impossível para as cidades ter ruas vigorosas e distritos em crescimento sem a preservação dos seus prédios antigos. Além disso, Amayu (2014) acredita que a preservação e o reúso de edifícios antigos têm benefícios econômico, ambiental e sociocultural para as comunidades urbanas. De modo geral, a proposta de reutilização de edificações, dotando-as de novo significado para a comunidade em que está inserida ao atribuir-lhe um novo uso, uma nova percepção do lugar e uma reinterpretação do ambiente original, torna possível reduzir espaços urbanos degradados e valorizar a memória do local. Com efeito, Ana Vitória Magalhães (2014) acredita que a intervenção deve permitir o resgate e a valorização da memória do edifício na cidade, através da geração de nova atividade, e, portanto, de novo uso ao edifício religioso, tornando-o parte do cenário cotidiano, com o "objetivo de conservar e renovar a cultura histórica edificada, fazer reuso dos espaços e recuperar e valorizar o território urbano" (MAGALHÃES, 2014).

Assim, é importante que os edifícios desativados sejam adequados às modificações ocorridas na sociedade, aos novos interesses que transformam os modos de vida e a cultura da comunidade envolvida, a partir da inserção de novos valores e conceitos, de novos modos de perceber o ambiente.

Espelhando-se nos exemplos ocorridos na Europa e no Canadá, este estudo apresenta a experiência de prática projetual vivenciada, durante o ano de 2015, no desenvolvimento de trabalho de conclusão de curso da graduação em Design de Ambientes da Escola de Design da Universidade do Estado de Minas Gerais (UEMG). Objetivava-se, com essa experiência, afirmar o potencial estratégico do design de ambientes no processo de ressignificação de uma edificação subutilizada, desativada, degradada ou abandonada localizada na região metropolitana de Belo Horizonte.

O desafio ora proposto baseia-se nas prerrogativas do design de ambientes, e considera que

as soluções em design cabem às diferentes demandas da contemporaneidade, e podem atingir os objetos, os processos, os serviços e seus respectivos 
sistemas, que num contexto amplo estão inseridos e fazem parte do ambiente. O design para ambientes apresenta-se, assim, como uma atividade voltada para a solução de "problemas" das pessoas em relação ao meio no qual estão inseridas. Tanto o arranjo quanto a ambiência dos ambientes são meios para a apresentação de solução em design, qualificando o uso das edificações, reduzindo a percepção dos não lugares, estimulando a convivência, facilitando a percepção de tempo e de espaço pelos usuários, construindo sentidos e concretizando desejos. Assim, cabe ao profissional designer de ambientes desenvolver propostas para os desafios relativos ao cotidiano, correspondendo às necessidades e às possibilidades dos indivíduos, promovendo melhor apropriação do lugar, bem-estar e qualidade de vida aos usuários. (BARBOSA, MACIEL e MOREIRA, 2014, p.1408).

Como se poderá ver nos resultados trazidos por este artigo, é possível afirmar o potencial estratégico do pensamento em design para ambientes no processo de ressignificação de uma edificação subutilizada, uma vez que a proposta projetual leva à comunidade nova possibilidade de uso e novo significado sem perder a importância imagética da arquitetura e o valor cultural do imóvel para a região. Além disso, contribui para a redução de espaços urbanos degradados e para a valorização da memória associada ao lugar.

\section{RESSIGNIFICAR, POR QUÊ?}

No campo do design, o termo ressignificação é utilizado para definir a revisão de uso dos objetos, uma reinterpretação dos artefatos produzidos pelo e para o homem a partir da alteração de seu conceito, seu sentido. Para Camilo Belchior (2011), uma das funções do design é ressignificar elementos, símbolos, valores, atributos e usos dos objetos que compõe o universo do homem. Em outros termos, ressignificar é dar um novo sentido ao objeto, modificando seu conceito, a percepção que as pessoas têm sobre ele, ou alterando sua interpretação original. É torná-lo coerente para o usuário, sob uma nova visão, transformando-o para o contexto em que está inserido. Para dar uma nova atribuição ao objeto, é necessário que a ressignificação esteja alinhada com elementos que expressam aquilo que as pessoas buscam, o que elas querem, desejam, ou seja, alinhada com as novas necessidades humanas.

O design é um processo de produção simbólica, que discute a relação contemporânea entre o homem, os objetos, a produção de desejo e o consumo (BELCHIOR, 2011). Portanto, cabe também ao designer ser o intermediário da readequação de elementos existentes ao cotidiano das pessoas, atribuindo um valor de novidade ou de diferenciação estética aos objetos preexistentes, a fim de conferir novos usos e novas relações simbólicas entre estes e os usuários. Como observa Belchior (2014), os objetos são portadores de signos e valores da vida cotidiana; alterações nessa cultura compartilhada mudam a forma como percebemos esses mesmos objetos, e, alterando-se as variáveis, é possível mudar a percepção que temos deles.

Diante do exposto, entende-se que esse pensamento pode ser perfeitamente aplicado aos ambientes, que também têm sua percepção modificada pelo dinamismo da vida contemporânea, e ao ser alterado fisicamente e simbolicamente, possibilita um novo uso, uma nova leitura e uma nova percepção do espaço. Dessa forma, "novas informações e experiências permitem ao sujeito reconhecer, nos mesmos signos, novas porções de significado e conferir a signos diferentes a mesma significação, 
ampliando ou restringindo, organizando ou desorganizando e construindo ou desconstruindo a significação atribuída" (BELCHIOR, 2014, p.75). Compreende-se, portanto, que a adição, modificação e/ou subtração de novas informações, alterando os signos contidos no ambiente, alteram a percepção e a experiência do usuário, proporcionando, assim, um novo significado ao espaço.

Para Andréia Marin e Kátia Kasper (2009), a percepção que o ser humano tem da natureza e do espaço habitado é marcada pela imaginação, pela afetividade, pela memória e pela sensibilidade estética. O significado da experiência estética está presente tanto nas construções do lugar habitado quanto na contemplação dos ambientes preservados, e as necessidades estéticas dos seres humanos estão relacionadas com os espaços do cotidiano e os âmbitos de vivência. Por isso, acreditase que a possibilidade de criação de novos modos de experimentar o espaço existente e as diferentes formas de interação com o meio são primordiais para a compreensão do processo de ressignificação. Compreende-se que a dinâmica do mundo atual altera a percepção, a interpretação e a relação do homem com os ambientes, pois traz novos valores, novas atividades, e, portanto, novas demandas de utilização e de apropriação do espaço.

\section{PROCESSO DE RESSIGNIFICAÇÃO DE EDIFICAÇÃO RELIGIOSA SUBUTILIZADA EM BELO HORIZONTE: O POTENCIAL ESTRATÉGICO DO DESIGN DE AMBIENTES}

Conforme já se sabe, este trabalho apresenta a experiência vivenciada por designers - docente e discente - no exercício da prática projetual do design de ambientes, durante o desenvolvimento de trabalho de conclusão de curso da graduação em Design de Ambientes da Escola de Design da UEMG.

A metodologia adotada nesse processo foi sistematizada em duas fases, ambas sob orientação docente. Na primeira, a graduanda se dedicou ao processo de briefing, consolidado a partir das seguintes etapas: investigação de edificações religiosas com potencial de ressignificação; definição da edificação conforme proposta, enquadrandoa como objeto de estudo; levantamento de informações referentes ao contexto sociocultural no qual a edificação está inserida; e análise de possibilidades de uso para a edificação selecionada. Os dados coletados e as análises realizadas indicaram a implantação de um café-sebo para ocupação dos ambientes do imóvel subutilizado, onde por anos funcionou uma igreja católica. Na segunda fase, dispondo como estratégia o fluxo metodológico do design para ambientes, a discente se ateve ao projeto dos espaços internos e externos do café-sebo.

Durante o processo de desenvolvimento do trabalho, uma questão chamou a atenção das pesquisadoras e merece destaque, por orientar traço peculiar do projeto. Após longo tempo de pesquisa de campo, ficou evidente a dificuldade de encontrar igrejas católicas subutilizadas, desativadas, degradadas ou abandonadas em Belo Horizonte e cidades adjacentes, apesar de todo esforço inquisitivo empreendido. Isso porque o cenário em Minas Gerais, ao que tudo indica, é bastante diferente do europeu e do canadense.

Apesar do número de pessoas que se declaram católicas ter diminuído em todo o Brasil, a redução em Minas Gerais foi menor do que a média nacional: a população católica urbana no estado é de $67,9 \%$, enquanto a média no país é de $62,1 \%$ (PARREIRAS, 2012). Percebe-se que isso se deve ao fato de Minas Gerais ter um legado histórico muito enraizado na fé católica, representado pelas tradições religiosas 
consagradas por festas e procissões e pelo grande número de igrejas católicas do barroco mineiro, fortemente presente em seu interior.

O processo da perda de frequentadores das igrejas católicas pode não ser tão profundo como o fenômeno observado na Europa e no Canadá, mas não quer dizer que não esteja acontecendo - apesar de possuir diferentes motivos. Enquanto nos países europeus e no Canadá a queda de fiéis se dá pela perda de valores tradicionais religiosos, no Brasil a perda de fiéis católicos se dá, principalmente, pelo crescimento de outras religiões. Levando-se em conta as pesquisas de 2000 e de 2010, apresentadas por Mateus Parreiras (2012), a fé evangélica cresceu 48,5\% no estado de Minas Gerais, passando de $13,6 \%$ para 20,2\%. Além disso, o espiritismo teve crescimento de $30 \%$ em 10 anos, passando de 1,6\% para 2,1\% dos mineiros. "Essa foi a maior redução católica de todos os censos", destaca Luciene Longo, demógrafa do Instituto Brasileiro de Geografia e Estatística - IBGE - (PARREIRAS, 2012).

Diante deste cenário e da consequente necessidade de muita procura, identificou-se uma edificação religiosa subutilizada localizada no bairro Gutierrez, na região oeste da capital mineira: a Igreja Santa Ermelinda (Figuras 01 a 08).
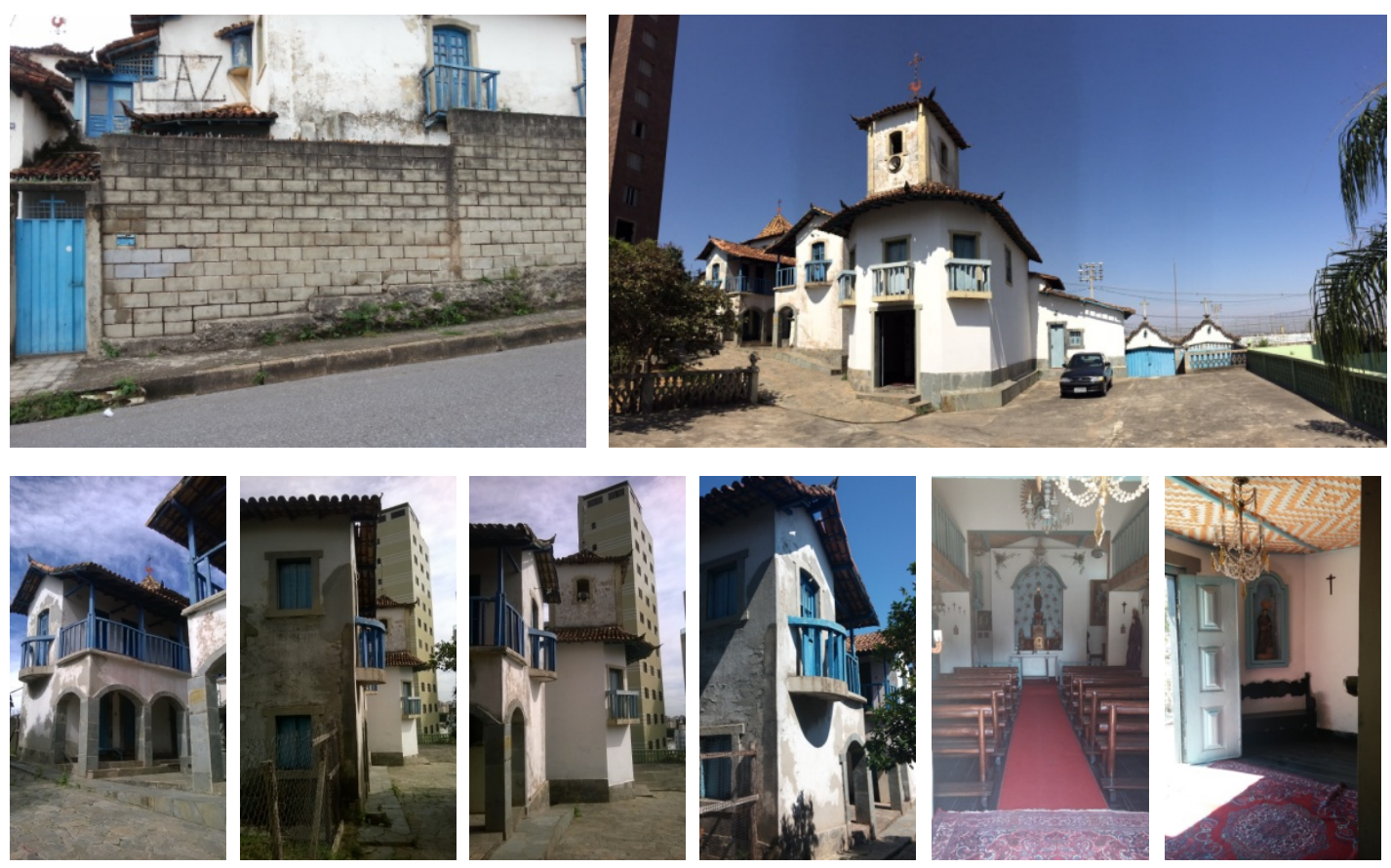

Figuras 01, 02, 03, 04, 05, 06, 07 e 08 - Imagens da fachada, da área externa e do interior da Igreja Santa Ermelinda, ano 2015.

Fonte: acervo das autoras.

A Igreja Santa Ermelinda está localizada em um lugar emblemático da cidade na Rua Eduardo Prado (Figura 09) -, um logradouro que demarca um abismo social: de um lado, o bairro Gutierrez de classe média alta, herdeiro do sobrenome de uma das famílias mais ricas e tradicionais de Belo Horizonte; do outro lado, a Vila São Jorge II, que faz parte do Aglomerado Morro das Pedras, comunidade formada nos idos da década de 1920 por vilas e favelas da região oeste da capital. 


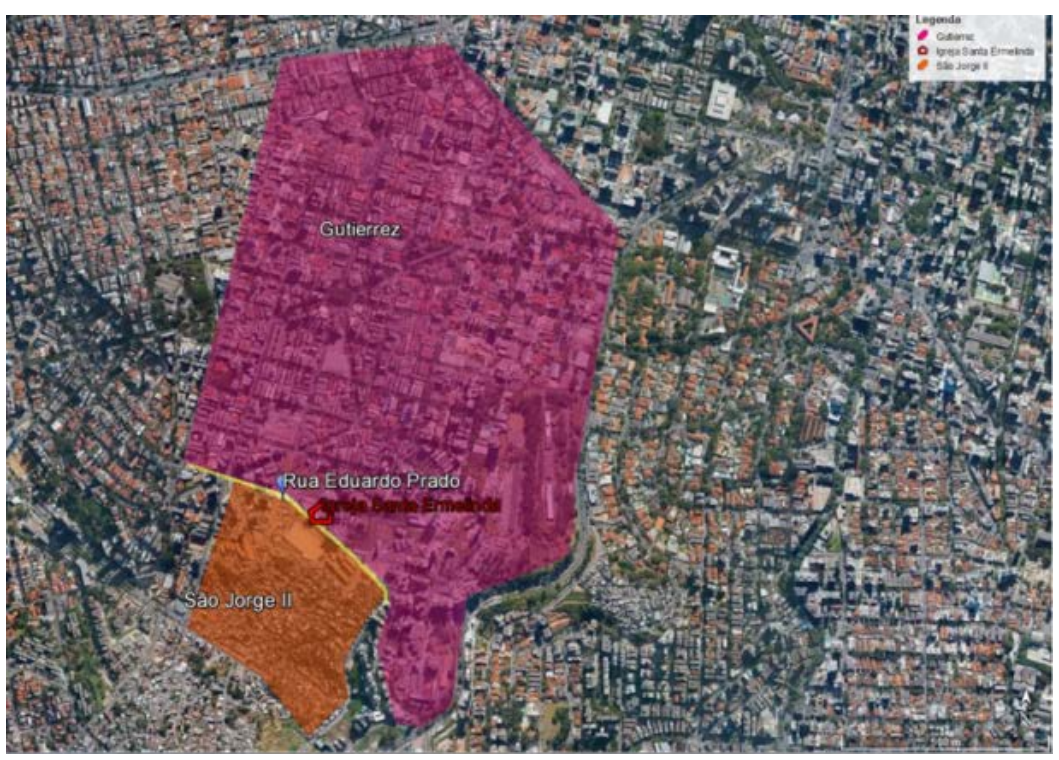

Figura 09 - Localização da Igreja Santa Ermelinda.

Fonte: Elaborado a partir do Google Earth.

A demanda induzida orienta o desafio de que é preciso ressignificar a Igreja Santa Ermelinda para que se possa recriar a relação entre indivíduos do entorno e ambiente. Recriar, pois, a partir da compreensão dos modos de viver da atualidade e de como isso afeta o cotidiano das pessoas, suas percepções de mundo e suas relações com o lugar vivido, a fim de se estabelecer uma nova identificação do usuário com o ambiente, proporcionando, assim, condições de atratividade mais capazes e consistentes para o edifício, promovendo a continuidade de sua utilização. Como diz Belchior (2011, p.24), os objetos existem no tempo e no espaço e vão perdendo sentidos antigos e adquirindo novos à medida que mudam de contexto. "Os objetos são portadores de signos e valores da vida cotidiana. Mudam os valores da vida, mudam os signos, mudam os objetos", mudam, portanto, os ambientes.

\subsection{Em busca de um novo uso, um novo significado}

Em seu livro Morte e Vida nas Grandes Cidades, Jane Jacobs (1961) explica como os moradores criam relações com a vizinhança e como essas relações influenciam na vitalidade urbana. Para a autora, as ruas e as calçadas são os espaços urbanos mais vitais e, dentre os elementos que os compõe, destacamos os edifícios antigos que, segundo Ednaldo Neto e Maria das Graças Palacios (2012), são cenários propícios para a instalação de livrarias e antiquários, estúdios, galerias, lojas de instrumentos musicais e materiais artísticos e cafés.

Por outro lado, a vitalidade urbana, também influenciada pela movimentação de pessoas nas ruas e nas calçadas, representa uma barreira ao crime, denominada por Jacobs (1961) como vigilância cidadã. Desse modo, um dos requisitos básicos para a vigilância cidadã é o número substancial de estabelecimentos e de outros locais públicos. Lojas, bares, padarias, restaurantes e outros estabelecimentos comerciais levam as pessoas a circularem onde eles existem, e a presença de pessoas atrai outras pessoas.

Também por isso, acredita-se ser importante que os ambientes ressignificados da Igreja Santa Ermelinda tenham uma proposta de uso diurno e noturno. Acredita-se, 
também, que o novo espaço deve ser democrático, de fácil acesso, heterogêneo, integrador, que facilite e permita a convivência em harmonia, carregado de sentido e de identidade, com possibilidade de apropriação por todos os habitantes do entorno.

Nesse contexto, e considerando as diversas variáveis do processo, a proposta para ressignificação da edificação religiosa em questão foi desta se tornar um cafésebo: um ambiente propício a encontros culturais, a troca de ideias, informações e conhecimentos, onde a comunidade se identifique e frequente, trazendo diferentes formas de expressão e renovando a memória do espaço edificado.

Além de muito bem se adequarem a um edifício antigo, como o da Igreja, as livrarias independentes traduzem a democratização do acesso ao livro e ao conhecimento, bem como à maior bibliodiversidade. Segundo dados de 2015 da Associação Nacional de Livrarias (ANL), a distribuição geográfica de livrarias de pequeno e médio porte pelo Brasil, classificadas como independentes, está diretamente relacionada à distribuição de renda e à qualidade do ensino básico oferecido. Quanto menor a renda e menor a qualidade de ensino de uma região, menor a presença de livrarias. Dessa forma, a pequena e a média livraria exercem um papel fundamental na democratização do acesso à leitura e nas necessidades primeiras da formação leitora de uma população carente de informações e conhecimentos, para se integrar a um mundo cada vez mais globalizado.

Lauri Martins (2015) destaca que, com a tendência dos livros eletrônicos, a possibilidade de um número maior de livros impressos usados surgirem para aquisição pelo sebo aumenta, ampliando a diversidade de exemplares para a fiel e potencial clientela do estabelecimento. Nesse sentido, Cinthya Oliveira (2015) aponta que "quem aparece na loja (sebo) é o amante do livro usado, aquele apaixonado pela poeira, pelo cheiro característico, pelo tom amarelado das páginas. Principalmente os colecionadores de livros raros, que não deixam de peregrinar pelos vários sebos da cidade".

Outra oportunidade observada nesse contexto é a de agregar serviços e produtos no rol do sebo, de maneira que o negócio seja entendido como cultura - ou seja, antes de vender livros, o sebo "vende" cultura (MARTINS, 2015). Ampliando esse escopo de concepção, dilata-se a possibilidade de agregar tendências relacionadas à cultura. Para além da literatura, têm-se oficinas de cinema, fotografia, dança, exposições de arte, apresentações musicais, dentre outras inúmeras possibilidades.

Assim, pode-se pensar que a proposta de ressignificação da igreja para o cafésebo seja um ambiente atrativo para o público local, uma vez que essa proposta de novo uso é, em suas características tangíveis e intangíveis, aberta, democrática e acessível aos possíveis usuários. Seus ambientes, então, devem ser visualmente atrativos e devem possuir uma linguagem estética coerente com a realidade do cotidiano daqueles que vivem e convivem naquela região, mesmo que possuam perfis tão distintos - fator determinante para a definição dessa nova proposta de uso para a edificação.

\subsection{Solução de design de ambientes}

Para o desenvolvimento do projeto de design de ambientes, a estudante se ateve às demandas de um espaço para o café, com mesas e cadeiras, cozinha e local para atendimento; um espaço para o sebo, em que se fez necessário pensar em estantes para livros, revistas, jornais, discos de vinil, CD's, DVD's, gibis - novos e 
usados -, além de caixa e sofás, poltronas, mesas e cadeiras; um espaço para manifestações culturais, tais como exposições de fotografia, projeção de filmes, apresentações musicais, oficinas de arte, feiras de livros, entre outros; e espaços que conferissem apoio necessário a essas atividades, como banheiros, estoques, depósito de material de limpeza e administração.

No pátio externo, criou-se o que denominamos design da paisagem, através de projeto de paisagismo e jardinagem com especificação de vegetação apropriada e mobiliário específico. Projetou-se, para este local, uma área livre central para as exposições, eventos e oficinas, além do palco para apresentações musicais e sarau de poesias (Figuras 10 e 11).

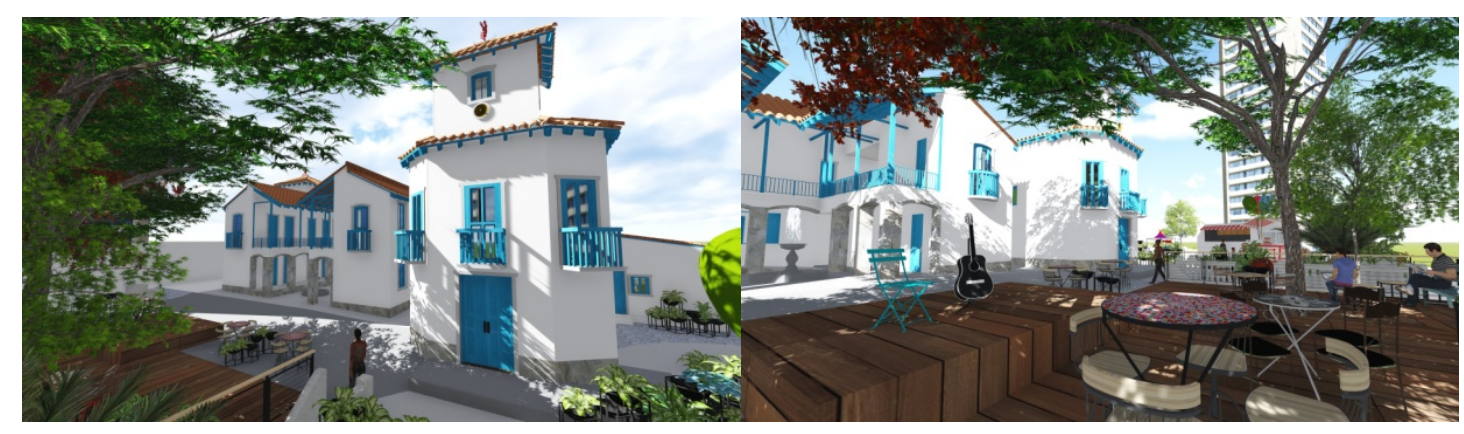

Figuras10 e 11 - Perspectivas do projeto de design de ambientes para o Café-sebo Santa Ermelinda. Fonte: Elaborado pela estudante.

Para criação do espaço do café, tomou-se partido da capela e da pequena copa existente na sacristia, para, respectivamente, área de atendimento e adequação da cozinha (Figuras 12, 13 e 14). Além disso, foi proposta a construção de um deck na área externa, para instalação de mais mesas, cadeiras e poltronas, além de espaços de leitura (Figuras 15 e 16).
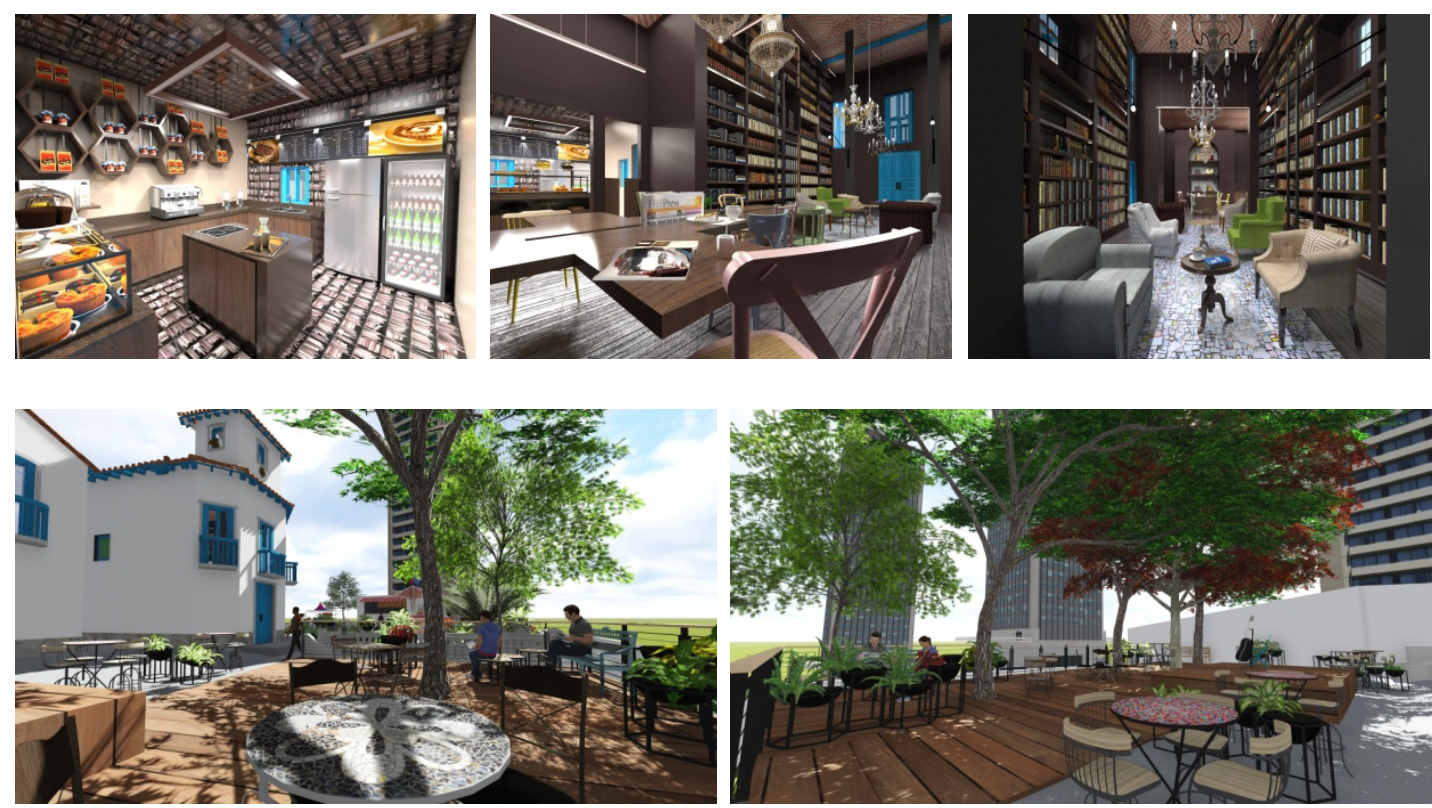

Figuras 12, 13, 14, 15 e 16 - Perspectivas do projeto de design de ambientes para o Café-sebo. Fonte: Elaborado pela estudante. 
O espaço interno da edificação localizada ao lado da capela foi utilizado para extensão do sebo, com salas de leitura (Figuras 17 e 18), caixa e banheiros acessíveis conforme normas técnicas.
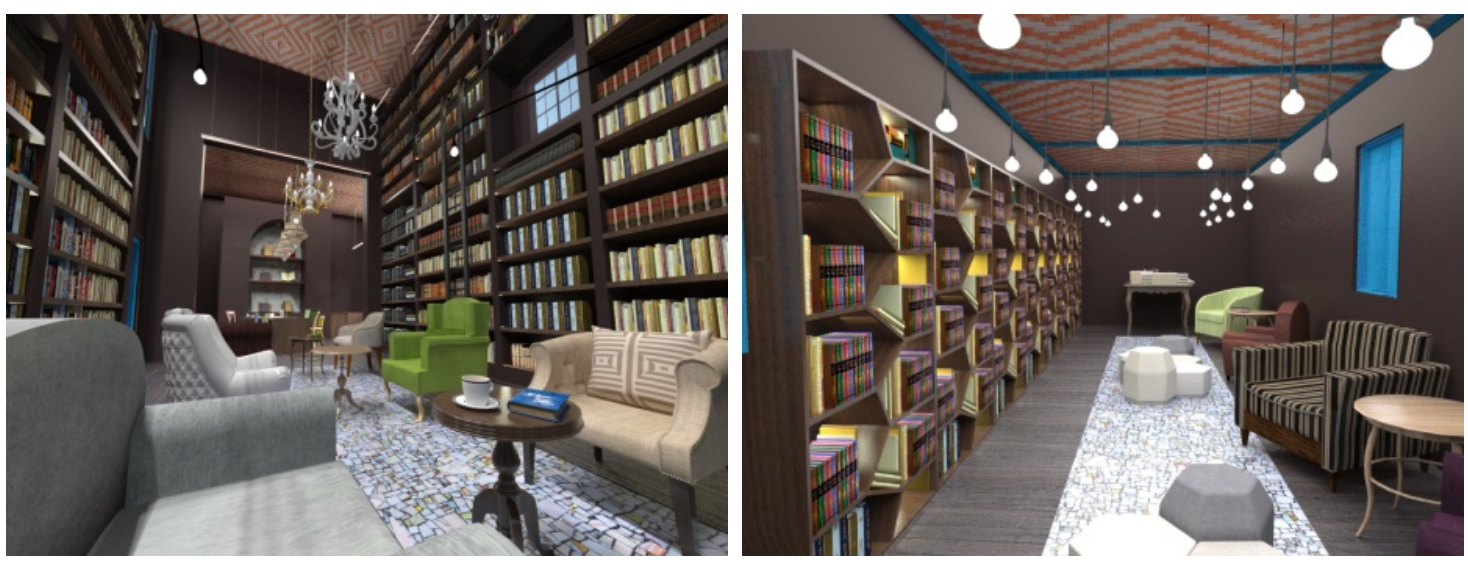

Figuras 17 e 18 - Perspectivas do projeto de design de ambientes para o Café-sebo Santa Ermelinda. Fonte: Elaborado pela estudante.

O mosaico, entendido como reunião de fragmentos diversos que, dispostos harmonicamente, formam um todo, foi a grande inspiração para o conceito do projeto. O conceito, por sua vez, orientou a ideação das ambiências, o que inclui a especificação das cores, das formas, das texturas, dos materiais e do mobiliário dos ambientes.

O mobiliário, em especial, foi definido a partir da ideia da "reunião de fragmentos diversos, que, dispostos harmonicamente, formam um todo". Desse modo, a combinação de diversos modelos diferentes de cadeiras, poltronas e mesas de apoio, com cores, materiais, texturas e acabamentos diversos, dispostos de forma harmônica, foi a solução encontrada para a criação de um espaço único e carregado de significado. Somado a isso, as escolhas foram feitas a partir da premissa do presente trabalho - a ressignificação -, de modo que os diferentes modelos ora citados fossem frutos da reutilização de elementos anteriormente descartados pela comunidade belohorizontina. Criaram-se, então, novas texturas e novos acabamentos, ou seja, novos objetos, dotados de novos significados ao serem inseridos em um novo contexto: um café-sebo em uma antiga igreja.

Assim como o mobiliário, a especificação dos acabamentos e revestimentos seguiram a premissa da ressignificação. Os lustres presentes na área de leitura do café, por exemplo, são os existentes na antiga capela: foram ressignificados. Além disso, para o antigo altar, onde antes eram expostas imagens de santos, foi proposta a exposição de livros raros, como uma vitrine de conteúdos importantes do sebo. Outro elemento criado para remeter à memória da antiga igreja foi a concepção da estante de alvenaria com prateleiras de madeira e com iluminação embutida fazendo a marcação de um desenho em forma de cruz, assim como a mesa que sai do altar.

O mosaico, em si, composto de ladrilhos ou pequenas peças coloridas e variadas, foi utilizado na paginação de piso da área externa - fazendo a marcação do paisagismo e a localização dos bancos - e de parte da área interna - evidenciando os lugares de leitura. No projeto, o piso das áreas internas foi mantido e restaurado, com exceção dos banheiros, que foram inteiramente reformados. 
Outra estratégia utilizada para estimular a apropriação do espaço pela comunidade foi a ideia de que seus moradores fizessem parte da execução de todo o projeto, por meio da contratação de mão de obra local - reformadores de móveis, pedreiros, pintores, fornecedores de pães, bolos e demais alimentos que seriam servidos no café. Enfim, todos os recursos humanos necessários para a materialização do projeto. O objetivo dessa ação é promover a participação da comunidade, criando laços de identidade e afetividade, possibilitando a apropriação do novo espaço por parte de todos os envolvidos.

\section{CONCLUSÃO}

Explorou-se a ideia de ressignificação como uma possibilidade para renovar a cultura edificada, promover reúso do espaço existente e reduzir espaços urbanos degradados a partir da premissa de que o mundo contemporâneo permite novos valores, novas atividades e, portanto, novas demandas de utilização e apropriação dos espaços da cidade.

A edificação escolhida, Igreja Santa Ermelinda, localiza-se na divisa do bairro Gutierrez com a Vila São José II, na região oeste na cidade de Belo Horizonte, entorno esse que conduziu e delimitou a definição de uma nova proposta de uso para a edificação. A partir da compreensão do significado dessa localização emblemática, pôde-se definir que o ambiente a ser projetado deveria ter características atrativas e consistentes para as diferentes classes econômicas, para promover a apropriação do espaço por habitantes do entorno. Ao compreender que a percepção do ser humano está ligada e marcada pela imaginação, afetividade e memória, foi possível propor um café-sebo. A partir dos livros, cafés e diferentes formas de expressão da arte, o ambiente se fez democrático, integrador e facilitador de trocas de ideias e conhecimentos entre os mais variados públicos e pensamentos.

Nesse processo, destaca-se o papel estratégico do designer de ambientes como ator criativo apto a (re)pensar os espaços de vivência humana, conferindo-lhes, essencialmente, sentido. Afinal, como define Vitor Papanek, a "tarefa essencial do designer é transformar o ambiente e as ferramentas do homem e, por extensão, o próprio homem".

\section{REFERÊNCIAS}

AMAYU, Ermias. New Uses for Old Churches: An Examination of the Effects of Planning Regulations on the Adaptive Reuse of Church Buildings. 2014. 73f. Dissertação (Mestrado em Urban and Regional Plannig) - Queen's University, School of Urban and Regional Planning. Kingston, Ontário, Canadá.

BARBOSA, Paula Glória; MACIEL, Bárbara Lima; MOREIRA, Samantha Cidaley de Oliveira. Novas maneiras de ensinar e aprender: o caso da disciplina prática projetual em design de ambientes. In: 11을 Congresso Brasileiro de Pesquisa e Desenvolvimento em Design, 2014, Gramado. Anais... São Paulo: Blucher, 2014. P. 1406-1417.

BELCHIOR, Camilo de Lelis. Reciclando os sentidos: o papel do design na ressignificação dos objetos. 2011. 171f. Dissertação (Mestrado em Design) - Escola de Design, Universidade Estadual de Minas Gerais, Belo Horizonte.

BELCHIOR, Camilo de Lelis. Reciclando os Sentidos. Contagem: Ed. do Autor, 2014. 
BENDAVI, Naftali. Europe's empty churches go on sale - hundreds of churches have closed or are threatened by plunging membership, posing question: what to do with unused buildings? The Wall Street Journal, Dow Jones \& Company, Inc. Nova lorque, 2 jan. 2015. Disponível em: <http://migre.me/u3bsc> Acesso em: 24 maio 2015.

GOTHE, Kerstin; NETSCH, Stefan. Abandoned and Re-Used Churches in Germany. In: REAL CORP - International Conference on Urban Planning and Regional Development in the Information Society, 2013, Roma. Anais... Roma: Manfred SCHRENK, 2013. P. 1079-1082.

JACOBS, Jane. Morte e vida de grandes cidades. São Paulo: Martins Fontes, 2000.

MAGALHÃES, Ana Vitória Tereza. Construir no construído, e a metamorfose da cultura urbana. Vitruvius - Minha Cidade, São Paulo, ano 15, n.171.04, online, out. 2014.

MARIN, Andréia Aparecida; KASPER, Kátia Maria. A Natureza e o Lugar Habitado Como Âmbitos da Experiência Estética: Novos Entendimentos da Relação Ser Humano Ambiente. Educação em Revista, Belo Horizonte, v.25, n.2, p.267-282, ago. 2009.

MARTINS, Lauri Tadeu Corrêa. Como montar um sebo - venda de livros usados. SEBRAE - Idéias de negócios. Disponível em: <http://migre.me/u3c8A >. Acessado em: 16 jun. 2015.

NETO, Ednaldo Ferreira Silva; PALACIOS, Maria das Graças Lima de Souza. Vitalidade urbana em Jane Jacobs. Salvador, 2012. In: III Seminário Internacional Urbicentros, 2012, Salvador. Anais... Salvador: UFBA/UFPB, 2012.

OLIVEIRA, Cinthya. 0 cotidiano dos donos de sebos em Belo Horizonte. Conselho Regional de Biblioteconomia da 6a Região, 2012. Disponível em: <http://migre.me/u3cAD>. Acesso em: 16 jun. 2015.

PARREIRAS, Mateus. Redução de católicos no interior de Minas é menor do que a média do país, diz IBGE. Estado De Minas online, Belo Horizonte, 30 jun. 2012. 